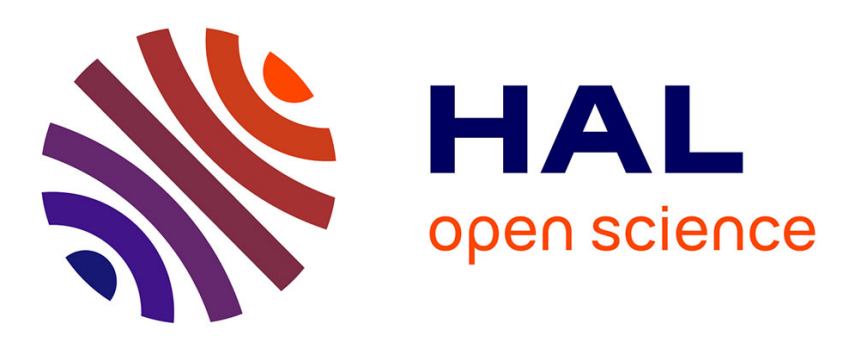

\title{
Division of labour and socially induced changes in response thresholds in associations of solitary halictine bees
}

Raphael Jeanson, Rebecca M. Clark, Carter T. Holbrook, Susan M. Bertram, Jennifer H. Fewell, Penelope F. Kukuk

\section{To cite this version:}

Raphael Jeanson, Rebecca M. Clark, Carter T. Holbrook, Susan M. Bertram, Jennifer H. Fewell, et al.. Division of labour and socially induced changes in response thresholds in associations of solitary halictine bees. Animal Behaviour, 2008, 76 (3), pp.593-602. 10.1016/j.anbehav.2008.04.007 . hal00319000

\section{HAL Id: hal-00319000 \\ https://hal.science/hal-00319000}

Submitted on 8 Sep 2008

HAL is a multi-disciplinary open access archive for the deposit and dissemination of scientific research documents, whether they are published or not. The documents may come from teaching and research institutions in France or abroad, or from public or private research centers.
L'archive ouverte pluridisciplinaire HAL, est destinée au dépôt et à la diffusion de documents scientifiques de niveau recherche, publiés ou non, émanant des établissements d'enseignement et de recherche français ou étrangers, des laboratoires publics ou privés. 
1 Division of labour and socially-induced changes in response thresholds in associations of 2 solitary halictine bees

3

4

5 Raphaël Jeanson ${ }^{1}$, Rebecca M. Clark ${ }^{2}$, C. Tate Holbrook ${ }^{2}$, Susan M. Bertram ${ }^{3}$, Jennifer H.

$6 \quad$ Fewell $^{2}$, Penelope F. Kukuk ${ }^{4}$

7

8

9 (1) Centre de Recherches sur la Cognition Animale, CNRS UMR 5169 - Université de

10 Toulouse, 118 Route de Narbonne, 31062 Toulouse, FRANCE

11 e-mail: jeanson@cict.fr

12

13

14

15 16

17

18

19

20

21

(2) School of Life Sciences, Arizona State University, Tempe, AZ 85287-4501, USA

(3) Department of Biology, Carleton University, 1125 Colonel By Drive, Ottawa, Ontario K1S 5B6, CANADA

(4) Division of Biological Sciences, The University of Montana, Missoula, MT 59812-4824, USA.

Running title: Jeanson et al.: Division of labour in halictine bees

Word count: 7937 


\section{4} 5

\section{ABSTRACT}

Division of labour is a recurrent property of social groups. Among the different models proposed to explain the origin of division of labour, response threshold models have garnered strong theoretical and empirical support. These models postulate that task specialisation can arise spontaneously from inter-individual variation in thresholds for responding to task-associated stimuli. Consequently, individuals with lower thresholds for a given task are more likely to become specialists. Self-reinforcement models expand this hypothesis by proposing that the successful performance of a task lowers an individual's threshold, increasing the probability that it will perform that task again. Although an important component of many models of division of labour, self-reinforcement can be difficult to test in real-world contexts. Here, we asked whether social experience modulates the individual response thresholds of normally solitary individuals. We focused on task performance during the early stages of nest construction in forced associations of the normally solitary halictine bee Lasioglossum (Ctenonomia) NDA-1. Within each pair, a strong behavioural asymmetry arose with one bee specialising in excavation and her nestmate in guarding the nest entrance. Individual performance of excavation by each bee was compared before and after being paired with a conspecific. After experiencing a social environment, individuals substantially increased their excavation performance. However, bees excavating more frequently in groups did not excavate differentially more afterward, as would be predicted by self reinforcement. The social context experienced by bees appears to promote behavioural differentiation leading to task specialisation, and to modulate response thresholds for excavation.

Keywords: division of labour, halictine bees, Lasioglossum NDA-1, nest construction, 47 response threshold, self-reinforcement, social modulation. 


\section{INTRODUCTION}

Division of labour, where individuals within a group perform different roles, is a recurrent property of sociality. Division of labour is believed to be a major determinant of the ecological success of group-living species (Oster \& Wilson 1978). It has been widely reported in invertebrates, including shrimp (Duffy et al. 2002), caterpillars (Underwood \& Shapiro 1999), thrips (Crespi 1992), hymenoptera (Wilson 1975, Oster \& Wilson 1978, Hölldobler \& Wilson 1990), and termites (Gerber et al. 1988). Division of labour is also common in vertebrates such as lions (Stander 1992), rats (Grasmuck \& Desor 2002), dolphins (Gazda et al. 2005), birds (Bednarz 1998), naked mole-rats (Sherman et al. 1991, Bennett \& Faulkes 2000) and humans (Patterson et al. 2004).

Several models have been proposed to explain the origin of division of labour (reviewed in Beshers \& Fewell 2001). Of these, fixed threshold response models postulate that division of labour can emerge spontaneously through variation among individuals in their internal response thresholds to task-specific stimuli (Robinson and Page 1989; Bonabeau et al. 1996, 1998). In performing a task, individuals with lower thresholds become the task specialists and reduce the likelihood that the same task will be performed by individuals with higher thresholds. Among eusocial insects, response thresholds have been empirically demonstrated for several tasks including fanning (O'Donnell \& Foster 2001, Jones et al. 2004), undertaking (Robinson \& Page 1988) and foraging (Stuart \& Page 1991, Fewell \& Page 2000). The requirements of this response threshold model are likely to be present at the origins of sociality and may thus contribute to the emergence of division of labour in social taxa. In support of this assertion, several studies have shown that division of labour can arise spontaneously in groups of normally solitary ant foundresses (Fewell \& Page 1999, HelmsCahan \& Fewell 2004) and solitary bees (Sakagami \& Maeta 1987, Jeanson et al. 2005).

In addition to fixed threshold models, some authors have proposed that experience can modulate task-associated response thresholds via positive feedback (Deneubourg et al. 1987, Plowright \& Plowright 1988, Theraulaz et al. 1998). These self-reinforcement models postulate that successful performance of a task can increase the probability of performing that task again. Conversely, unsuccessful performance or lack of opportunity to perform the task can reduce the likelihood that individuals will perform it, given later opportunities to do so. Reinforcement can therefore produce worker specialization and influence the organisation of work within colonies. Self-reinforcement effects on division of labour have some empirical support in social insects. For instance, the individual response thresholds of bumble bee workers for fanning to control nest climate vary with experience (Weidenmüller 2004). 
Reinforcement can generate behavioural differentiation within an initially homogeneous group of individuals. In the ant Cerapachys biroi, Ravary et al. (2007) found that division of labour can arise spontaneously among originally undifferentiated individuals depending on their foraging experience. Successful foragers became foraging specialists, while workers that were unsuccessful in their initial foraging attempts became brood tending specialists. Reinforcing mechanisms have also been proposed to contribute to the establishment of dominance hierarchies, such as in wasps where hierarchical interactions reinforce the probability that a given individual will dominate or loose in subsequent encounters (Theraulaz et al. 1995, Camazine et al. 2001). However, tests of the contribution of self-reinforcement to the production of division of labour are generally rare and are, to our knowledge, absent in non-eusocial systems. This limits the application of the model to most social taxa. In addition, when studied entirely within a social environment, the relative contribution of selfreinforcement per se may be hindered by the influence of social interactions on division of labour. An alternative approach is to test for persistent reinforcement effects on individual response thresholds after task specialists and non-specialists have been separated.

Because their social systems range from solitary through communal, and in some cases eusocial, halictine bees are a useful taxon to examine the evolution of division of labour. In facultatively social bees, females may nest either solitarily or in groups depending partly on ecological pressures, such as predation and nest availability (Dunn and Richard 2003). Division of labour between foraging and guarding frequently arises in these associations. In carpenter bees of the tribe Xylocopini, nests established by solitary foundresses may be later usurped by a second foundress with the dominant females specialising in egg-laying and foraging while the non-reproductive females guard the nest entrance (Hogendoorn \& Velthuis 1999). Conversely, in ceratinine and allodapine bees, dominant females usually guard the nests and subordinates forage (Hogendoorn \& Schwarz 1998).

During the early stages of nest construction within forced pairs of the normally solitary halictine bee Lasioglossum (Ctenonomia) NDA-1, previous work revealed that interindividual variation in the propensity to excavate, coupled with spatial separation generated by social interactions, promotes the emergence of division of labour between tunnel excavation and nest guarding (Jeanson et al. 2005). In the present study we ask whether social experience can temporally modulate the individual response thresholds of normally solitary bees. We test the prediction of self reinforcement that individuals increase their probability of performing a task after becoming the specialist for that task. Focusing on the early stages of 
nest construction in associations of the normally solitary bee L. (Ctenonomia) NDA-1, we compare individual excavation performance before and after bees experience a social environment. We also examine these artificially constructed social groups for the emergence of division of labour.

\section{MATERIAL AND METHODS}

\section{Study species}

124 Females of the normally solitary Lasioglossum (Ctenonomia) NDA-1 were collected in the Cobboboonee State Forest (latitude: 141.53 E, longitude: 38.19 S, elevation: $70 \mathrm{~m}$ ),

126 Southwestern Victoria, Australia during December 2006. A previous excavation of $L$.

127 (Ctenonomia) NDA-1 revealed that only two of 19 nests contained two females, confirming 128 their status as primarily solitary nesting (McConnell-Garner and Kukuk 1997). Bees were 129 collected by netting above nest aggregations and were taken immediately to the laboratory, 130 where they were placed individually in Petri dishes supplied with a damp tissue and a 1:1 131 honey water mixture. The day before the first experiment, two groups of bees were marked 132 with enamel paint on the thorax and both sides of the abdomen. Bees were randomly assigned 133 to two treatments: a 'social' treatment where bees experienced the presence of a conspecific 134 during a portion of the experiment, and a solitary treatment (hereafter control bees) where 135 bees did not encounter conspecifics for the duration of the experiment. Bees were stored 136 overnight at ambient temperature $\left(16^{\circ} \mathrm{C}\right)$ before experimental treatment.

\section{Experimental design}

139 We first quantified individual activity levels of each bee in the absence of nest construction or social interactions, by measuring their movement rates in circle tubes (as per Breed et al 1978). We then placed bees individually into observation nests to assess their excavation performance while alone. Following this, to assess the impact of social environment on task performance, bees were separated into a control group of individuals that remained solitary, and an experimental group in which bees were paired with others that showed initially similar levels of excavation behaviour. All bees, solitary or paired, were placed into fresh observation nests and observed for 18 hours. Following this, all bees were placed individually into new nests and observed again to assess whether excavation behaviour was affected differentially depending on social context (Figure 1). 
151 To examine whether differences in the nature of social interactions or task performance may be influenced by differences in an individual's general activity level, we placed all bees individually into a circular plastic tube (inner diameter: $0.42 \mathrm{~cm}$, length: $20 \mathrm{~cm}$ ), and quantified the amount of time they were active (Fig. 1). The circular tube was placed in a plastic box with long tubular lights on each side to ensure homogeneous lighting during data collection. The temperature was maintained at $27 \pm 0.5^{\circ} \mathrm{C}$. Each trial began 2 min after introducing the bee into the box, and lasted for 5 min. During trials we recorded the percentage of time a bee was walking or sitting/grooming and measured the time that individuals took to cover a distance of $10 \mathrm{~cm}$ without stopping or turning. This experiment took place between $09 \mathrm{~h} 30$ and $13 \mathrm{~h} 00$.

Tunnel construction by single individuals (Days 1-2)

After assessment of activity levels, all bees were introduced individually (between $14 \mathrm{~h} 00$ and $15 \mathrm{~h} 00$ ) into observation nests ( $15 \mathrm{~cm}$ deep $\times 12$ wide $\mathrm{cm} \times 3 \mathrm{~mm}$ thick) and allowed to excavate tunnels. Observation nests were filled with dampened sifted soil collected from the nesting area in the field. Each nest was connected by a clear plastic tube $(4 \mathrm{~cm})$ to a clear plastic vial (2-cm diameter, $4 \mathrm{~cm}$ high) containing a 1:1 honey water mixture. A small indentation of $1 \pm 0.1 \mathrm{~cm}$ was made in the soil to encourage the bee to dig a single vertical gallery. Prior to introduction of bees, nests were cooled to $5{ }^{\circ} \mathrm{C}$. After the bees were introduced into the nests, the nests were placed in a climate controlled room at $15 \mathrm{~h} 00$. The climate controlled room was kept at $31 \pm 1{ }^{\circ} \mathrm{C}$ with a photoperiod of 15 hours of light and 9 hours of darkness; darkness started at $19 \mathrm{~h} 00$. The bees were allowed to excavate for 18 hours. their Petri dishes. Using a ruler, we measured the length of each bee's tunnel to quantify their digging performance and assign them to treatment groups. We also digitally photographed each nest to more precisely quantify tunnel depths using ImageJ (see below).

Social interactions (Day 2)

Bees were randomly assigned to either the solitary ( $n=30$ bees) or social treatment groups $(\mathrm{n}=35$ pairs). Bees assigned to the social treatment were paired using individual digging performance data. To minimize initial inter-individual differences in propensity to dig, we matched individuals with similar digging performance (the two bees that dug the most were paired, and so on, until the two bees that dug the least were paired). Prior to placing 
184 them together in a nest, each pair was introduced into a circular plastic tube, under the same

185 light and temperature conditions described for activity levels, to quantify their social interactions (see below) (Fig. 1). Observations began 2 min after bees were introduced, and lasted $7 \mathrm{~min}$. Three types of inter-individual encounters were observed in the social assays. In all cases, the inter-individual distance of the two bees was less than $2 \mathrm{~mm}$ apart when these encounters were recorded:

(1) Head to head encounter (a frontal encounter)

(2) Head to back encounter (a forward-moving bee encountered the back of a sitting bee)

(3) Back to back encounter (one or both bees backed in the tube and encountered each other)

Once contact was established, we then recorded the outcomes of interactions. These included:

(1) U-turn to head to head (following a head to back encounter, one bee made a U-turn resulting in a head to head encounter)

(2) Withdraw (one bee made a U-turn and moved away from the other)

(3) Back (one bee backed away after encountering the other bee)

(4) C-posture (a bee curled her abdomen, giving a C-shaped position with the sting pointed at the other female)

(5) Bite (one bee bit the other)

(6) Lunge (one bee quickly lunged toward the other)

(7) Block (one bee curled the abdomen to prevent the other bee from passing)

(8) Pass (bees passed by one another, requiring the rotation of each bee while moving past the other venter to venter; we identified the bee initiating the pass, the bee allowing the pass and instances where both bees mutually passed). Tunnel construction by single and paired individuals (Days 2-3)

(9) No response (sitting and/or self-grooming)

Following the circle tube assays for social interactions, we placed each solitary

Control bees were introduced individually into the circular tube under the same light and temperature conditions for $9 \mathrm{~min}$, but because they were alone, their social behaviour was not assessed. This experiment took place between $10 \mathrm{~h} 00$ and $12 \mathrm{~h} 30$ on day 2 .

$$
\text { treatment bee and each pair from the social treatment into different observation nests. Bees }
$$
were maintained in the same pairs for circle tube assays and observation nests. Four sessions 
218 of twenty scans each were performed every $6 \mathrm{hr}$ over the next $18 \mathrm{hr}$ ( 240 scans in total).

219 Individual nests were scanned every $5 \mathrm{~min}$. During each scan we recorded the location and 220 behaviours of each bee, following Jeanson et al (2005). Behaviours consisted of:

(1) Excavate (the bee excavated dirt with her mandibles),

(2) Push (the bee pushed loose soil in the tunnel towards the nest entrance or vial),

(3) Tamp (the bee tamped loose dirt into side walls with her abdomen (Batra 1964)),

(4) Gate-Keep (the bee sits in the tube connecting the nest and the vial) honey water solution in the vial. These behaviours were either not associated with specific tasks or were rarely performed (feeding), and thus were not used in division of labour or task specialization analyses. The tasks of pushing and tamping generally occurred together, and so were combined for analyses.

Bee locations were categorized as: Vial, Tube, Tunnel, Bottom (dead end of a gallery). The three focal tasks were spatially segregated within the nest; excavation occurred at the bottom of a gallery, pushing/tamping took place in the tunnel or in the tube, and gate keeping occurred close to the nest entrance. Excavation could only be performed by one bee at a time within a tunnel, but pushing/tamping and gate-keeping could be performed by both bees simultaneously. After 18 hours, the nests were digitally photographed to measure the lengths

Tunnel construction by single individuals (Days 3-4)

To determine whether individual response thresholds changed with experience, bees were removed from their paired (social treatment) or solitary (control treatment) nests and transferred individually into new observation nests at $15 \mathrm{~h} 00$ on day 3 . After $18 \mathrm{hr}$, bees were removed and the total tunnel length of each nest was measured. At the end of the experiments, bees were euthanized and preserved in $95 \%$ ethanol.

\section{Data analysis}

Tunnel length

Each nest was photographed with a digital camera. From the pictures, the tunnels were traced using the software ImageJ (http://rsb.info.nih.gov/ij) to precisely measure their total length. There was a strong correlation between the total length and area of the tunnels (Pearson correlation test: $r_{86}=0.92, P<0.001$ ). Because there was no variation in the width of tunnels (which equalled approximately the width of a bee), we subsequently compared 
excavation performance across treatments with reference to tunnel length. For the subsequent analysis, we subtracted $0.9 \mathrm{~cm}$ to the length measured to take into account the indentation made in the observation nests.

\section{Number of excavation bouts}

To quantify the influence of experience and social context on excavation behaviour, we compared the number of excavation bouts performed across days. Because we did not observe behaviour on days 1-2 or days 3-4, we used the relationship between excavation bouts and tunnel length for control bees that dug alone on days 2-3 to estimate the number of excavation bouts for all bees that dug alone on days 1-2 and days 3-4. There was a strong positive correlation between tunnel length and the number of excavating bouts observed (linear regression: $\mathrm{F}_{1,29}=106.82, P<0.001, \mathrm{R}=0.89$ ). The digging rate, estimated using the inverse of the regression coefficient was 2.5 bouts/cm (i.e. the number of observed bouts required to dig $1 \mathrm{~cm}$; note this is the number of observed bouts, not the number of actual bouts required to dig $1 \mathrm{~cm}$, as each nest was only scanned 80 times during the 18 hour period). Each bee's number of excavation bouts was then estimated for days 1-2 and days 3-4 by multiplying her tunnel length by the average digging rate.

\section{Quantification of division of labour}

Following Jeanson et al. (2005), we categorized individuals as performing one of three tasks: excavating, pushing/tamping, or gate keeping. Division of labour within each pair was quantified using an index developed by Gorelick et al. (2004). To calculate the index, we generated a matrix of task performance, in which each cell showed the frequency with which a specific individual was observed performing a specific task. The matrix was then normalized so that the total of all cells added to one. From this matrix, we calculated the Shannon's index H(indiv) for the distribution of tasks across individuals (Gorelick et al. 2004). Dividing the mutual entropy between tasks and individuals by the marginal entropy of

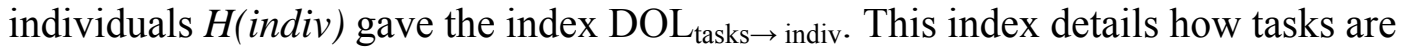
distributed across individuals and ranges between 0 (no division of labour) and 1 (complete division of labour). Pairs in which nestmates performed only one of the focal tasks or in 
The daily intensity of division of labour was compared using repeated measures ANOVA. We used a MANOVA after square root transformation to compare the number of behavioural bouts performed by pairs and control bees on days 2-3. We examined the excavation performance over days between control bees and individuals within pairs by fitting linear mixed-effects models (lme procedure, Pinheiro and Bates 2000) after square root transformation of the number of excavation bouts. We started with a full mode including time (days), group (control, HFE, LFE; see below) and their first and second term interactions as fixed effects. Observation nests and days were set as random factors. From the full model, the minimal model was obtained by successively deleting non significant terms using the parsimony principle based on the Akaike's Information Criterion (Pinheiro and Bates 2000). The number of behavioural bouts performed individually on days 2-3 was compared using $t$ tests after square root transformation. Pearson correlation tests were used to test the relationship between tunnel length across successive days, the relationship between the probability of passing and the intensity of division of labour, and the relationship between activity level and excavation performance. Statistical tests were two-tailed and performed with SPSS (v. 11.0, SPSS Inc., Chicago, USA), except linear mixed models which were done using the statistical package R (R Development Core Team, 2005).

\section{RESULTS}

\section{Task performance in social versus solitary contexts}

We compared performance rates of solitary and paired bees for the three tasks: excavation, pushing/tamping and gate keeping on days 2-3. Bees in the social treatments collectively performed more behavioural bouts than control bees (Fig. 2). Pairs performed approximately twice the number of excavations (MANOVA: $\mathrm{F}_{1,62}=15.89, P<0.001$ ) and push/tamp bouts (MANOVA: $F_{1,62}=28.50, P<0.001$ ) as control bees. Pairs also displayed about seven times more gate-keeping than control bees (MANOVA: $\mathrm{F}_{1,62}=106.44, P<0.001$ ). The total per capita task performance was about 1.6 higher for pairs than for control bees ( $t$-test: $t_{96}=4.62$, $P<0.001)$ and paired bees performed individually about 3.5 times more gate-keeping than

\section{Differentiation within pairs for excavation behaviour}

Within each pair, we identified a higher frequency excavator (hereafter HFE) as the

318 bee performing more excavation bouts than her nestmate (hereafter LFE: lower frequency 
excavator). One pair was discarded from this analysis because neither bee dug. In two pairs, because both bees displayed the same number of excavation bouts, one bee was randomly assigned as the HFE. Note that the first bee to be introduced into the nest was not more likely to become the HFE (Chi ${ }^{2}$ test: $\left.\chi_{1}=0.13, P=0.72\right)$.

We used linear mixed models to examine the variations in excavation performance between HFE, LFE and control bees over time (Table 1). There was no difference in the number of excavation bouts performed by control, HFE and LFE bees on Days 1-2 (Fig. 3). There was a marginally significant variation in the excavation rates of control bees across the three days of the experiment. When bees were paired together on days 2-3, their behaviour diverged, such that one bee (HFE) excavated more than the other and LFE bees maintained a similar excavation performance as on days 1-2. Pairs were separated on day 3 and individual excavation behaviour was re-assessed in isolation. When placed alone in observation nests on days 3-4, LFE bees dug more than they had while alone on days 1-2 or in pairs on days 2-3. In contrast, HFE excavated more on days 2-3 and on days 3-4 than on days 1-2 but their performance did not differ between days 2-3 and days 3-4. The tunnels dug by HFE and LFE on days 3-4 were, respectively, 1.65 and 2.5 times longer than on days 1-2.

\section{Task specialization and level of division of labour in pairs}

Bees designated as HFE and LFE for excavation behaviour showed differential performance of other tasks while together (G-test: $\left.\mathrm{G}_{2}=10.56, P<0.01\right)$. There were no differences between HFE and control ( $t$-test: $\left.t_{62}=1.9, P=0.06\right)$, LFE and control ( $t$-test: $\mathrm{t}_{62}=0.06, P=0.54$ ) or LFE and HFE in their pushing/tamping behaviour (paired $t$-test: $\mathrm{t}_{33}=1.22$, $P=0.23$ ) (for all tests, corrected $\alpha=0.017$ ) (Figure 4). Both LFE ( $t$-test: $\mathrm{t}_{62}=6.33, P<0.001$ ) and HFE ( $t$-test: $\mathrm{t}_{62}=3.12, P=0.003$ ) displayed significantly more gate keeping bouts than did control bees. The LFE bees also displayed significantly more gate keeping bouts than HFE (paired $t$-test: $\mathrm{t}_{33}=3.03, P=0.005$ ) (for all tests, corrected $\alpha=0.017$ ).

For each pair, the DOL metric was computed for each session of twenty scans during the 18 hour period on days 2-3. One pair did not dig during days 2-3 and was excluded from the analysis. For the three focal tasks, the total performance of each pair equalled at least 36 bouts (median $=84 ; 1^{\text {st }}$ quartile $=67 ; 3^{\text {rd }}$ quartile=101) and each bee within a pair performed at least 11 bouts (median $=54 ; 1^{\text {st }}$ quartile $=31 ; 3^{\text {rd }}$ quartile=54). Division of labour did not change over time (repeated-measures ANOVA: $F_{3,93}=0.27, P=0.85$ ); therefore data were pooled for analysis. Across the four sessions of twenty scans ( 80 scans per pair), the average $\mathrm{DOL}_{\text {tasks } \rightarrow}$ indiv equalled $0.26 \pm 0.04\left(\mathrm{n}=34 ;\right.$ median $=0.13 ; 1^{\text {st }}$ quartile $=0.09 ; 3^{\text {rd }}$ quartile $\left.=0.45\right)$. There was 
no correlation between tunnel length and $\mathrm{DOL}_{\text {tasks } \rightarrow \text { indiv }}$ (Pearson correlation test: $r_{34}=-0.28$, $354 P=0.10)$.

\section{Activity levels}

357 Control and paired bees did not differ in the amount of time they spent walking when they were alone in the circle tubes (control mean \pm SEM: $0.37 \pm 0.06$; paired bees mean \pm SEM: $0.34 \pm 0.03$; $t$-test: $\left.t_{98}=-0.47, P=0.64\right)$. For paired bees, there was no correlation between individual activity level (time spent walking) and the length of their tunnel dug alone on days 1-2 or on days 3-4 (Pearson correlations: days 1-2: $r_{70}=0.09, P=0.44$; days 3-4: $r_{70}=-0.18$, $P=0.14)$. Likewise, there was no correlation between activity level and tunnel length on any of the three days for control bees (Pearson correlations days 1-2: $r_{30}=0.07, P=0.71$; days 2-3: $r_{30}=0.33, P=0.07$, or days 3-4: $\left.r_{30}=0.16, P=0.39\right)$. Activity level did not predict which bees would subsequently be categorized as HFE or LFE (HFE mean \pm SEM: $0.32 \pm 0.05$; LFE mean \pm SEM: $0.39 \pm 0.05 ;$-test: $\left.t_{66}=-1.18, P=0.24\right)$.

\section{Social interactions}

The median number of encounters observed per pair of bees was $11\left(1^{\text {st }}\right.$ quartile $=6.5 ; 3^{\text {rd }}$ quartile $=18.5$ ). Fourteen of 35 pairs displayed at least one C-posture (a total of 15 bees). In all but one of these pairs only one bee displayed C-postures. The bees that displayed C-postures did not differ from their counterparts in activity level (C-posture bee mean \pm SEM: $0.33 \pm$ 0.06; other bee mean \pm SEM: $0.34 \pm 0.04$; $t$-test: $\left.\mathrm{t}_{68}=-0.2, P=0.84\right)$. Among the 15 bees displaying $\mathrm{C}$ postures, half (7) later became the HFE. Twenty five of 35 pairs displayed at least one pass (median $=7 ; 1^{\text {st }}$ quartile $=2 ; 3^{\text {rd }}$ quartile $=11$ ). Across pairs, the median proportion of encounters ending in a pass was $0.28\left(1^{\text {st }}\right.$ quartile $=0 ; 3^{\text {rd }}$ quartile $\left.=0.55\right)$. Whenever possible, we identified which individuals initiated the pass during each encounter. There was no difference in activity level between bees initiating more passes (mean \pm SEM: $0.32 \pm 0.07$ ) and bees allowing passes (mean \pm SEM: $0.43 \pm 0.05$ ) ( $t$-test: $\left.t_{48}=-1.23, P=0.22\right)$. In 22 out of

38032 pairs with an identifiable HFE, it was possible to identify which bee initiated passes.

381 Among the bees that initiated more passes, 11 became HFE and 11 were LFE. There was no correlation between the probability to pass in circle tubes and DOL $\mathrm{L}_{\text {tasks } \rightarrow \text { indiv }}$ (Pearson correlation test: $\left.r_{34}=0.10, P=0.58\right)$.

\section{DISCUSSION}


In this study, we first examined whether division of labour can arise during the early stages of nest construction in forced associations of solitary individuals. In our experimental conditions, three tasks were available: excavation, gate-keeping and pushing/tamping. A behavioural differentiation regularly occurred within pairs, with one bee specialising in excavation at the bottom of the gallery and her nestmate primarily guarding the nest entrance. Pushing/tamping, which is a spatially intermediate task, was performed equally by both individuals. These results support our conclusions from earlier work that division of labour can emerge in pairs of normally solitary halictine bees (Jeanson et al. 2005).

In the present study, bees were paired so to minimize the initial interindividual differences in their propensity to dig. However, once in pairs, the bees altered their behaviours. One bee specialised in excavation and performed about two times more excavation bouts than when she was previously alone. In contrast, her nestmate decreased her excavation performance while simultaneously increasing her gate keeping. These data support the assertion that division of labour can spontaneously emerge from social dynamics, even at the origins of sociality. The differentiation between bees that were initially similar in behaviour before they were placed in social groups indicates that the observed task specialization is indeed an effect of social dynamics and not simply a reflection of individual variation within the group (Fewell \& Page 1999). Similar patterns of task specialisation have been found in associations of normally solitary foundresses of the harvester ant Pogonomyrmex californicus (Helms Cahan \& Fewell 2004, Jeanson \& Fewell subm.).

\section{Self-reinforcement and task differentiation}

Under the hypothesis of self-reinforcement, the more an individual performs a task, the lower its associated threshold becomes (Theraulaz et al. 1998). The excavation specialist (HFE) was thus expected to subsequently display a higher propensity to dig after taking over the task of excavation in pair groups. In our experiments, the HFE indeed performed more excavation on days 3-4 than on days 1-2, after they dug intensively on days 2-3. However, LFE performed the task even more frequently after experiencing the social context. Indeed, the excavation performance of LFE was similar on days 1-2 and days 2-3 but dramatically increased (by a factor 2.5) on days 3-4 and reached about $85 \%$ of the performance achieved by the HFE specialists on days 2-3. Conversely, bees maintained alone did not vary in their excavation performance across days. While self-reinforcement might account for the increased performance of excavating specialists, it is unlikely to explain the enhanced level of digging among non-specialist bees. The increased excavation behaviour of both specialists 
and non specialists compared to their excavation behaviour prior to being paired suggests that the earlier social context experienced by bees induced a delayed modulation of response thresholds for excavation which cannot be explained by self-reinforcement alone, or any other existing models of task performance and/or division of labour. In addition, division of labour did not increase during the first 18 hours of nest construction, contrary to the hypothesis that self-reinforcement amplifies behavioural differentiation over time.

Although a growing body of empirical evidence supports for the role of response threshold variation in the production and maintenance of division of labour, few empirical studies have examined the contribution of self-reinforcement to task specialisation. To our knowledge, such evidence has been reported only in eusocial taxa, including ants (Ravary et al. 2007), wasps (Theraulaz et al. 1995) and bumblebees (Weidenmuller 2004). Our finding that self-reinforcement is absent during the early stages of nest construction in forced associations of normally solitary individuals suggests that self-reinforcement may be a derived organizational mechanism that enhances division of labour in evolved societies but does not appear spontaneously in incipient groups. Alternatively, self-reinforcement may not apply to all available tasks. Using a similar experimental paradigm, further studies should test whether self-reinforcement is involved during nest construction in communal and eusocial halictine bees that burrow in soil.

\section{Social modulation of excavation behaviour}

Although our data do not support self-reinforcement as the primary mechanism driving task differentiation, they clearly show that excavation is socially modulated; both bees showed a reduction in their individual response thresholds for excavation after they experienced the presence of a nestmate. A different pattern has been documented in associations of normally social individuals. For instance, the ant Camponotus japonicus dug significantly larger amounts of sand in associations than when the same ants worked separately but did not alter individual digging performance before and after being paired (Chen 1937 a, b). Similarly, in social halictine bees such as the communal L. (Chilalictus) hemichalceum (Jeanson et al. 2005) and the eusocial L. zephyrum (Michener et al. 1971), individuals that experience repeated contact show enhanced digging activity over bees that are housed without social contact. An increase in the propensity to express a behaviour when others express it is known as social facilitation (Clayton 1978, Webster \& Fiorito 2001). Social facilitation could be attributed to a reduction in the individual response thresholds associated with a specific task depending on the perception of conspecifics already engaged in 
the same activity. A comparative study between populations with different social structures should aid in our understanding of how social context-induced modifications in individual response thresholds may have paralleled social transitions in halictine bees. In particular, we predict that communal bees maintained alone should have higher individual response thresholds for excavation than solitary bees because repeated social contact appears to be mutually stimulating within social populations.

How did social modulation of excavation behaviour occur in our study? One hypothesis is that exposure to a larger nest volume than usually experienced by single bees stimulated paired individuals to reach similar depths after they were separated. Indeed, the nests excavated by pairs were about two times larger than nests dug concurrently by solitary control bees, and single individuals from the social treatment excavated longer tunnels the next day. A direct test for this effect would involve placing individual bees in different-sized tunnels and measuring their excavation performance when subsequently alone. At the molecular level, we speculate that social modulation of task performance may have been mediated by biogenic amines. In invertebrates, biogenic amines (e.g. octopamine, serotonin, dopamine) are important modulators of behaviour (Pflüger and Stevenson 2005). Earlier social experience has been shown to alter individual behaviours via changes in amine concentrations in various species of arthropods including spiders (Punzo \& Punzo 2001), crustaceans (Huber et al. 2001), crickets (Stevenson et al. 2005) and ants (Cuvillier-Hot \& Lenoir 2006). In addition, changes in amine titres are a significant source of variation in response thresholds and contribute to the regulation of division of labour in insect colonies. For instance, amines modulate the response threshold of honeybee for sucrose (Scheiner et al. 2002), and octopamine enhances the foraging response to brood pheromones (Barron et al. 2002, Barron \& Robinson 2005). In our study, we hypothesize that the social context experienced by normally solitary bees affected their levels of amines, which may in turn have induced a modulation of excavation behaviours. Further studies should investigate whether modifications of individual response thresholds correlate with variation in amine titres depending on social context.

\section{Aggression and task allocation}

Aggression and dominance interactions can contribute to the establishment of reproductive division of labour both in invertebrates (e.g. ants: Monnin \& Peeters 1999; wasps: Sledge et al. 2001) and in vertebrates (e.g. spotted hyenas: Creel et al. 1997). Aggressive interactions among eusocial insect workers can also regulate allocation for non- 
reproductive tasks. In the wasp Polybia occidentalis, biting interactions among workers modulate the probability of foraging (O'Donnell 2003, 2006). In the present study, the initiator or recipient of aggressive acts (e.g. C-posture) was not more likely to specialise in excavation or guarding within pairs, and division of labour apparently did not emerge through social contention. However, this does not mean that social interactions did not contribute to task specialisation. Indeed, Jeanson et al (2005) found that the low probability of passing in $L$. NDA-1 generated a spatial segregation of solitary bees within the nest, which consequently reduced the turnover among tasks and indirectly reinforced task asymmetry with pairs (Jeanson et al. 2005).

\section{Guarding in solitary and social contexts}

A surprising result of our study was the extreme increase in gate keeping behaviour by the paired bees in comparison to when they were solitary. As with excavation, this task also showed extensive task specialization, with the bee who excavated less frequently being more likely to gate-keep. In our experiments, guarding was observed more frequently in pairs than in solitary nests, and pairs dug nests that were twice as deep. On average, the entrance of the nest was guarded $50 \%$ of the time by at least one bee in pairs versus less than $10 \%$ in solitary nests. In pairs, only one bee excavated at a time and the time spent digging or sitting by the HFE at the bottom of the tunnel equalled approximately the time spent by her nestmate sitting in the tube. The increased performance in gate-keeping in pairs may have resulted from the predominant occupancy of the bottom of the gallery by the excavation specialist while, as a result, her nestmate mainly occupied upper part of the nest and engaged in gate-keeping. Although there was no possibility of predators or other intruders in our experiment, gate-keeping is behaviourally similar to guarding in a natural context. In many halictine species, the nest consists of a burrow that enters the soil with lateral cells that are provisioned with pollen and nectar (Michener 1964). The entrance of the nest is generally constricted and fits the head or abdomen size of a bee. Bees guard the nest by blocking the nest entrance with their head or by presenting their abdomen (Batra 1964, Knerer 1969). In the halictine bee Agapostemon virescens, guarding is responsible for the accrued resistance to attack by cleptoparasites in communal nests in comparison to solitary nesting (Abrams and Eickwort 1981). Abrams and Eickwort (1981) proposed that social nesting permits bees to (1) guard nests at all times, (2) conserve digging effort per nestmate, and (3) dig deeper burrows reaching soil levels with optimal water content. During the incipient stages of sociality, associations of initially solitary individuals may therefore have benefited from improved nest 
defence through increased guarding and improved ability to reach soils with optimal water content. These benefits may have promoted transitions to communal sociality in halictine bees.

\section{Acknowledgements}

We would like to thank National Science Foundation's Integrative Organismal Systems collaborative research grant number 0446415 for supporting this research. We thank $\mathrm{P}$. Michelena and C. Andalo for useful discussions. S.M.B. would also like to thank Carleton University for partial support through start-up funds.

\section{References}

Abrams, J. \& Eickwort, G. C. 1981. Nest switching and guarding by the communal sweat bee Agapostemon virescens (Hymenoptera, Halictidae). Insectes Sociaux, 28, 105-116.

Barron, A. B. \& Robinson, G. E. 2005. Selective modulation of task performance by octopamine in honey bee (Apis mellifera) division of labour. Journal of Comparative Physiology A-Neuroethology Sensory Neural and Behavioral Physiology, 191, 659-668.

Barron, A. B., Schulz, D. J. \& Robinson, G. E. 2002. Octopamine modulates responsiveness to foraging-related stimuli in honey bees (Apis mellifera). Journal of Comparative Physiology a-Neuroethology Sensory Neural and Behavioral Physiology, $188,603-610$.

Batra, S. W. T. 1964. Behavior of the social bee, Lasioglossum zephyrum, within the nest (Hymenoptera, Halictidae). Insectes Sociaux, 2, 159-186.

Bednarz, J. C. 1988. Cooperative hunting in Harris' hawks. Science, 239, 1525-1527.

Bennett, N. C. \& Faulkes, C. G. 2000. African Mole-Rats: Ecology and Eusociality. Cambridge, UK: Cambridge University Press.

Beshers, S. N. \& Fewell, J. H. 2001. Models of division of labor in social insects. Annual Review of Entomology, 46, 413-440.

Bonabeau, E., Theraulaz, G. \& Deneubourg, J.-L. 1996. Quantitative study of the fixed threshold model for the regulation of division of labour in insect societies. Proceedings of the Royal Society of London. Series B, 263, 1565-1569.

Bonabeau, E., Theraulaz, G. \& Deneubourg, J. L. 1998. Fixed response thresholds and the regulation of division of labor in insect societies. Bulletin of Mathematical Biology, 60, 753-807. 
Breed, M. D., Siverman, J. M. \& Bell, W. J. 1978. Agonistic behavior, social interactions, and behavioral specialization in a primitively eusocial bee. Insectes Sociaux, 25, 351-364.

\section{Camazine, S., Deneubourg, J. L., Franks, N. R., Sneyd, J., Theraulaz, G. \& Bonabeau,} E. 2001. Self-Organization in Biological Systems. Princeton: Princeton University Press.

Chen, S. C. 1937a. Social modification of the activity of ants in nest-building. Physiogical Zoology, 10, 420-436.

Chen, S. C. 1937b. The leaders and followers among the ants in nest-building. Physiogical Zoology, 10, 437-455.

Clayton, D. A. 1978. Socially facilitated behavior. Quarterly Review of Biology, 53, 373-392.

Creel, S., Creel, N. M., Mills, M. G. L. \& Monfort, S. L. 1997. Rank and reproduction in cooperatively breeding African wild dogs: Behavioral and endocrine correlates. Behavioral Ecology, 8, 298-306.

Crespi, B. J. 1992. Eusociality in Australian gall thrips. Nature, 359, 724-726.

Cuvillier-Hot, V. \& Lenoir, A. 2006. Biogenic amine levels, reproduction and social dominance in the queenless ant Streblognathus peetersi. Naturwissenschaften, 93, 149153.

Deneubourg, J.-L., Goss, S., Pasteels, J. M., Fresneau, D. \& Lachaud, J.-P. 1987. Selforganization mechanisms in ant societies (2): learning in foraging and division of labor. In: From Individual to Collective Behavior in Social Insects (Ed. by Pasteels, J. M. \& Deneubourg, J. L.). Basel: Birkhauser.

Duffy, J. E. 1996. Eusociality in a coral-reef shrimp. Nature, 381, 512-514.

Dunn, T. \& Richards, M. H. 2003. When to bee social: interactions among environmental constraints, incentives, guarding, and relatedness in a facultatively social carpenter bee. Behavioral Ecology, 14, 417-424.

Fewell, J. H. \& Page, R. E. 1999. The emergence of division of labour in forced associations of normally solitary ant queens. Evolutionary Ecology Research, 1, 537-548.

Fewell, J. H. \& Page, R. E. 2000. Colony-level selection effects on individual and colony foraging task performance in honeybees, Apis mellifera L. Behavioral Ecology and Sociobiology, 48, 173-181.

Gazda, S. K., Connor, R. C., Edgar, R. K. \& Cox, F. 2005. A division of labour with role specialization in group-hunting bottlenose dolphins (Tursiops truncatus) off Cedar Key, Florida. Proceedings of the Royal Society B-Biological Sciences, 272, 135-140.

Gerber, C., Badertscher, S. \& Leuthold, R. H. 1988. Polyethism in Macrotermes bellicosus (Isoptera). Insectes Sociaux, 35, 226-240. 
Gorelick, R., Bertram, S. M., Killeen, P. R. \& Fewell, J. H. 2004. Normalized mutual entropy in biology: quantifying division of labor. American Naturalist, 164, 678-682.

Grasmuck, V. \& Desor, D. 2002. Behavioural differentiation of rats confronted to a complex diving-for-food situation. Behavioural Processes, 58, 67-77.

Helms Cahan, S. \& Fewell, J. H. 2004. Division of labor and the evolution of task sharing in queen associations of the harvester ant Pogonomyrmex californicus. Behavioral Ecology and Sociobiology, 56, 9-17.

Hogendoorn, K. \& Schwarz, M. P. 1998. Guarding specialisation in pre-reproductive colonies of the allodapine bee Exoneura bicolor. Ethology Ecology \& Evolution, 10, $67-$ 77.

Hogendoorn, K. \& Velthuis, H. H. W. 1999. Task allocation and reproductive skew in social mass provisioning carpenter bees in relation to age and size. Insectes Sociaux, 46, 198-207.

Hölldobler, B. \& Wilson, E. O. 1990. The Ants. Cambridge, Massachusetts: Belknap Press of Harvard University Press.

Huber, R., Panksepp, J. B., Yue, Z., Delago, A. \& Moore, P. 2001. Dynamic interactions of behavior and amine neurochemistry in acquisition and maintenance of social rank in crayfish. Brain Behavior and Evolution, 57, 271-282.

Jeanson, R., Kukuk, P. F. \& Fewell, J. H. 2005. Emergence of division of labour in halictine bees: contributions of social interactions and behavioural variance. Animal Behaviour, 70, 1183-1193.

Jeanson, R. \& Fewell, J.H. Influence of the social context on division of labor in ant foundress associations. Submitted.

Jones, J. C., Myerscough, M. R., Graham, S. \& Oldroyd, B. P. 2004. Honey bee nest thermoregulation: diversity promotes stability. Science, 305, 402-404.

Knerer, G. 1969. Synergistic evolution of halictine nest architecture and social behavior. Canadian Journal of Zoology, 47, 925-930.

McConnell-Garner, J. \& Kukuk, P. F. 1997. Behavioral interactions of two solitary, halictine bees with comparisons among solitary, communal and eusocial species. Ethology, 103, 19-32.

Michener, C. D. 1964. Evolution of the nests of bees. American Zoologist, 4, 227-239.

Michener, C. D., Brothers, D. J. \& Kamm, D. R. 1971. Interactions in colonies of primitively eusocial bees: artificial colonies of Lasioglossum zephyrum. Proceedings of the National Academy of Sciences USA, 68, 1241-1245. 
Monnin, T. \& Peeters, C. 1999. Dominance hierarchy and reproductive conflicts among subordinates in a monogynous queenless ant. Behavioral Ecology, 10, 323-332.

O'Donnell, S. 2003. The development of biting interactions and task performance in a tropical eusocial wasp. Behaviour, 140, 255-267.

O'Donnell, S. 2006. Polybia wasp biting interactions recruit foragers following experimental worker removals. Animal Behaviour, 71, 709-715.

O'Donnell, S. \& Foster, R. L. 2001. Thresholds of response in nest thermoregulation by worker bumble bees, Bombus bifarius nearcticus (Hymenoptera : Apidae). Ethology, 107, 387-399.

Oster, G. F. \& Wilson, E. O. 1978. Caste and Ecology in the Social Insects. Princeton, New Jersey: Princeton University Press.

Patterson, C. J., Sutfin, E. L. \& Fulcher, M. 2004. Division of labor among lesbian and heterosexual parenting couples: correlates of specialized versus shared patterns. Journal of Adult Development, 11, 179-189.

Pflüger, H. J. \& Stevenson, P. A. 2005. Evolutionary aspects of octopaminergic systems with emphasis on arthropods. Arthropod Structure \& Development, 34, 379-396.

Pinheiro, J. C. \& Bates, D. M. 2000. Mixed-Effects Models in S and S-PLUS. New-York: Springer-Verlag.

Plowrigth, R. C. \& Plowright, C. M. S. 1988. Elistism in social insects: a positive fed-back model. In: Interindividual Behavioral Variability in Social Insects (Ed. by Jeanne, R. L.), pp. 419-431. Boulder, Colorado: Westview Press.

Punzo, F. \& Punzo, T. 2001. Monoamines in the brain of tarantulas (Aphonopelma hentzi) (Araneae, Tireraphosidae): Differences associated with male agonistic interactions. Journal of Arachnology, 29, 388-395.

Ravary, F., Lecoutey, E., Kaminski, G., Chaline, N. \& Jaisson, P. 2007. Individual experience alone can generate lasting division of labor in ants. Current Biology, 17, 13081312.

Robinson, G. E. \& Page Jr, R. E. 1988. Genetic determination of guarding and undertaking in honey-bee colonies. Nature, 333, 356-358.

Robinson, G. E. \& Page, J. R. E. 1989. Genetic basis for division of labor in an insect society. In: The Genetics of Social Evolution (Ed. by Breed, M. D. \& Page, J. R. E.), pp. 61-80. Boulder, Colorado: Westview Press Inc. 
Sakagami, S. F. \& Maeta, Y. 1987. Sociality, induced and/or natural, in the basically solitary small carpenter bees (Ceratina). In: Animal Societies: Theories and Facts (Ed. by Itô, Y., Brown, J. L. \& Kikkawa, L.), pp. 1-16. Tokyo: Japan Scientific Societies Press.

Scheiner, R., Pluckhahn, S., Oney, B., Blenau, W. \& Erber, J. 2002. Behavioural pharmacology of octopamine, tyramine and dopamine in honey bees. Behavioural Brain Research, 136, 545-553.

Sherman, P.W., Jarvis J.U.M. \& Alexander, R.D. 1991. The Biology of the Naked MoleRat. Princeton USA: Princeton University Press.

Sledge, M. F., Boscaro, F. \& Turillazzi, S. 2001. Cuticular hydrocarbons and reproductive status in the social wasp Polistes dominulus. Behavioral Ecology and Sociobiology, 49, 401-409.

Stander, P. E. 1992. Cooperative hunting in lions: the role of the individual. Behavioral Ecology and Sociobiology, 29, 445-454.

Stevenson, P. A., Dyakonova, V., Rillich, J. \& Schildberger, K. 2005. Octopamine and experience-dependent modulation of aggression in crickets. Journal of Neuroscience, 25, 1431-1441 .

Stuart, R. J. \& Page, R. E. 1991. Genetic component to division of labor among workers of a Lepthoracine ant. Naturwissenschaften, 78, 375-377.

Theraulaz, G., Bonabeau, E. \& Deneubourg, J.-L. 1998. Response threshold reinforcement and division of labour in insect societies. Proceedings of the Royal Society of London, Series B, 265, 327-332.

Theraulaz, G., Bonabeau, E. \& Deneubourg, J. L. 1995. Self-organization of hierarchies in animal societies - the case of the primitively eusocial wasp Polistes dominulus Christ. Journal of Theoretical Biology, 174, 313-323.

Underwood, D. L. A. \& Shapiro, A. M. 1999. Evidence for division of labor in the social caterpillar Eucheira socialis (Lepidoptera: Pieridae). Behavioral Ecology and Sociobiology, 46, 228-236.

Webster, S. \& Fiorito, G. 2001. Socially guided behaviour in non-insect invertebrates. Animal Cognition, 4, 69-79.

Weidenmüller, A. 2004. The control of nest climate in bumblebee (Bombus terrestris) colonies: interindividual variability and self reinforcement in fanning response. Behavioral Ecology, 15, 120-128.

Wilson, E. O. 1975. Sociobiology. The New Synthesis. Cambridge, Massachusetts: Harvard University Press. 
690 Table 1: Results of the linear mixed model fitted by maximum likelihood for the square root

691 of the number of excavation bouts performed individually; with parameter estimates (i.e.

692 fixed-effects estimates), approximate standard errors, degrees of freedom, t-estimates (ratio

693 between the estimates and the standard errors) and P values. Control represents bees placed

694 individually into observation nests. HFE and LFE represent bees within pairs; each bee within

695 a pair was designated HFE (Higher Frequency Excavator) or LFE (Lower Frequency

696 Excavator) based on the number of observed times they excavated while in the pair. Nests

697 refer to observation nests. Formulae follow the convention of the R language.

698

699 Random effects

700 Formula: $\sim$ days|nests

701 Standard Deviation: Intercept $=1.37$ Days $=0.54 \quad$ Residual $=1.35$

702

703 Fixed effects

704 Formula: $\sqrt{ }($ individual excavation bouts $) \sim$ group $\times$ days + group $\times$ days $^{2}$

705

$\begin{array}{rccccc} & \text { Estimate } & \text { SE } & \text { df } & \text { t-value } & P \\ \text { Intercept } & 2.07 & 0.17 & 222 & 11.86 & <0.0001 \\ \text { Control } \times \text { Days } & 1.18 & 0.56 & 222 & 2.08 & 0.04 \\ \text { HFE } \times \text { Days } & 2.54 & 0.52 & 222 & 4.84 & <0.0001 \\ \text { LFE } \times \text { Days } & -1.51 & 0.53 & 222 & -2.87 & 0.004 \\ \text { Control } \times \text { Days }^{2} & -0.52 & 0.29 & 222 & -1.79 & 0.07 \\ \text { HFE } \times \text { Days }^{2} & -0.98 & 0.27 & 222 & -3.63 & 0.0004 \\ \text { LFE } \times \text { Days }^{2} & 1.12 & 0.27 & 222 & 4.14 & <0.0001\end{array}$




\section{Figure legends}

710 Figure 1: Sequence of experimental design.

711

712 Figure 2: Box plots of the total number of excavation, push/tamp and gate keeping bouts

713 performed by control bees and pairs on days 2-3. * indicates statistical significance. Boxes

714 show median value, $25^{\text {th }}$ and $75^{\text {th }}$ percentiles and outliers.

716 Figure 3: Box plots of excavation bouts performed daily by control, HFE (higher frequency

717 excavator, i.e. bee performing more excavation bouts than her nestmate within pairs), and

718 LFE (lower frequency excavator) bees. Boxes show median value, $25^{\text {th }}$ and $75^{\text {th }}$ percentiles 719 and outliers.

721 Figure 4: Box plots of the number of behavioural bouts performed by control, HFE (higher 722 frequency excavator) and LFE (lower frequency excavator) bees on days 2-3. For each 723 behaviour, different letters indicate significant statistical differences. Boxes show median 724 value, $25^{\text {th }}$ and $75^{\text {th }}$ percentiles and outliers. 


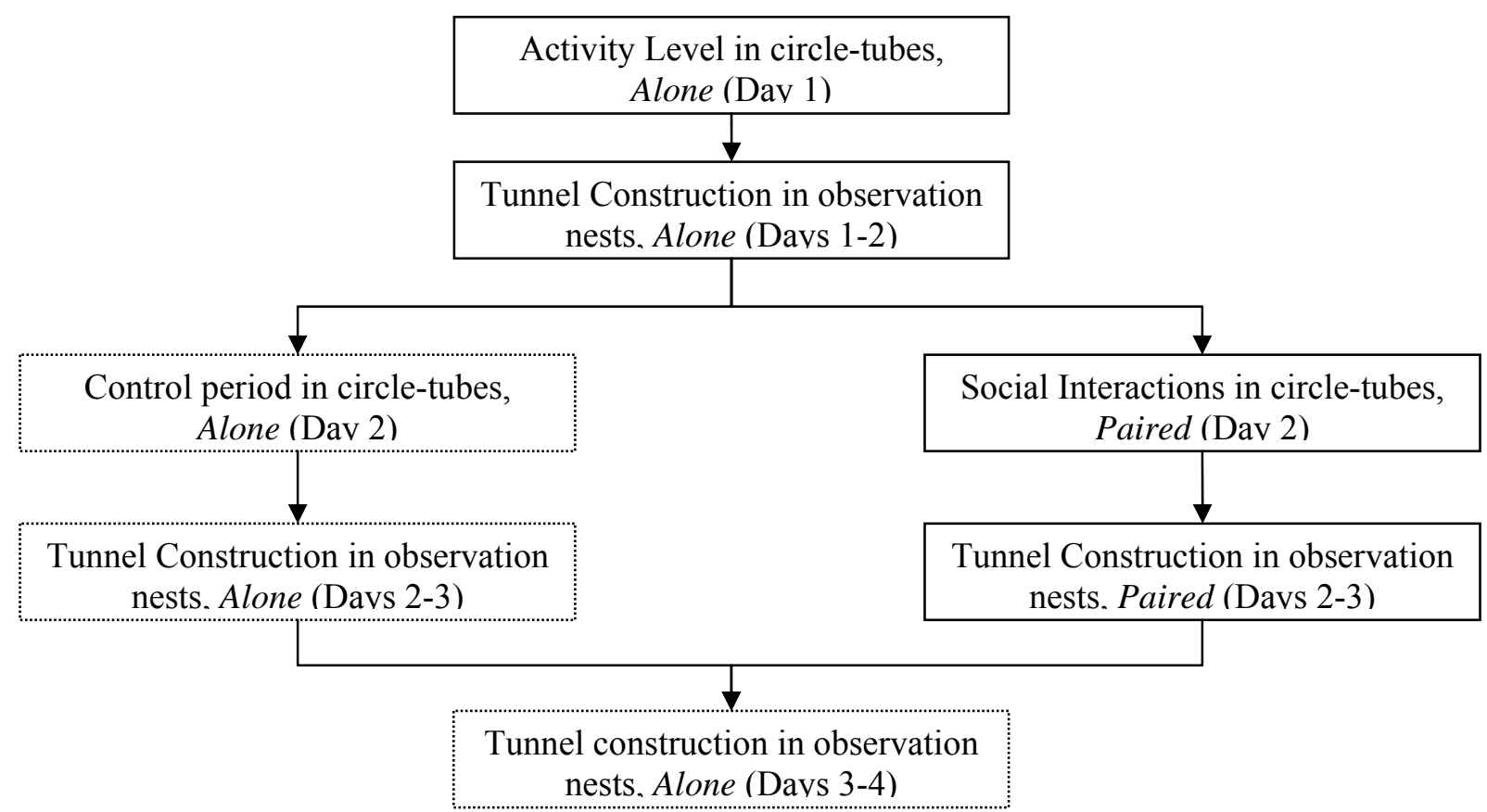


Figure 2

731

732

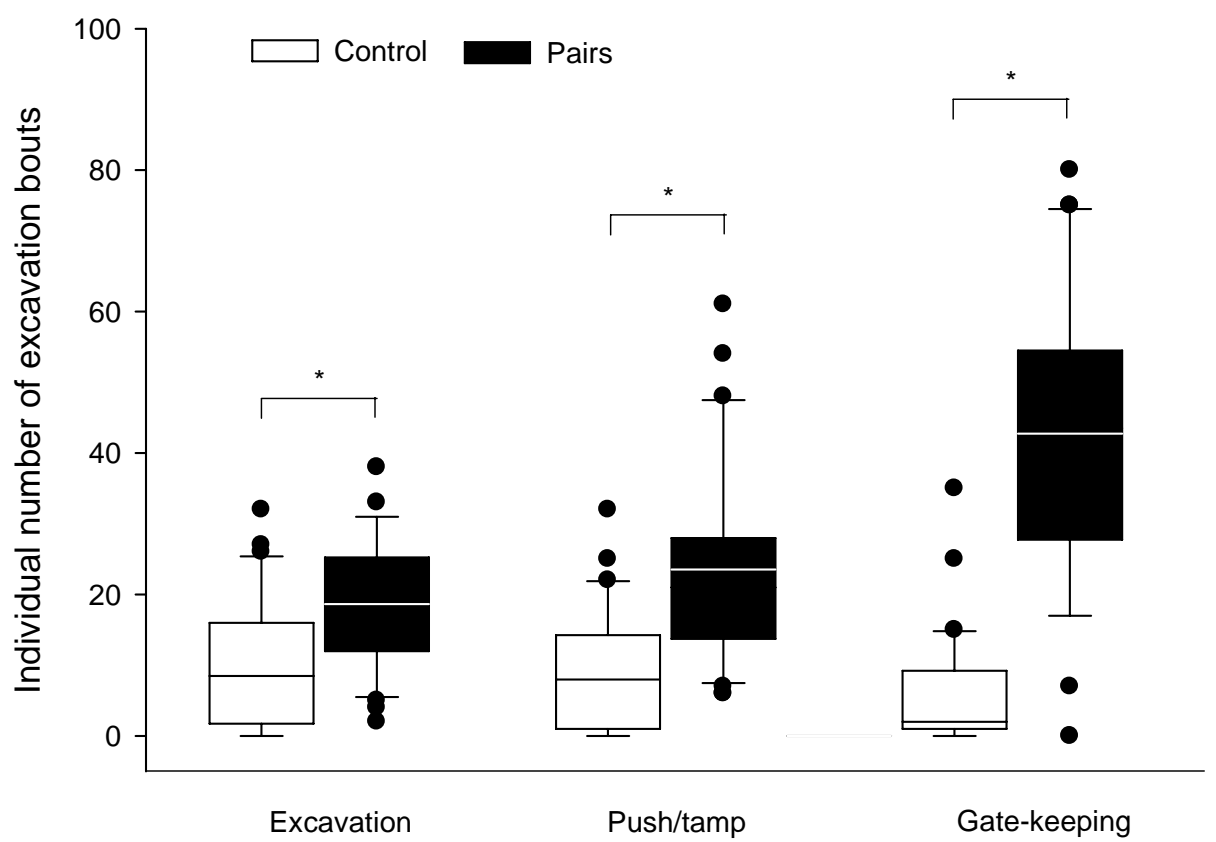

733 
$734 \quad$ Figure 3

735

736

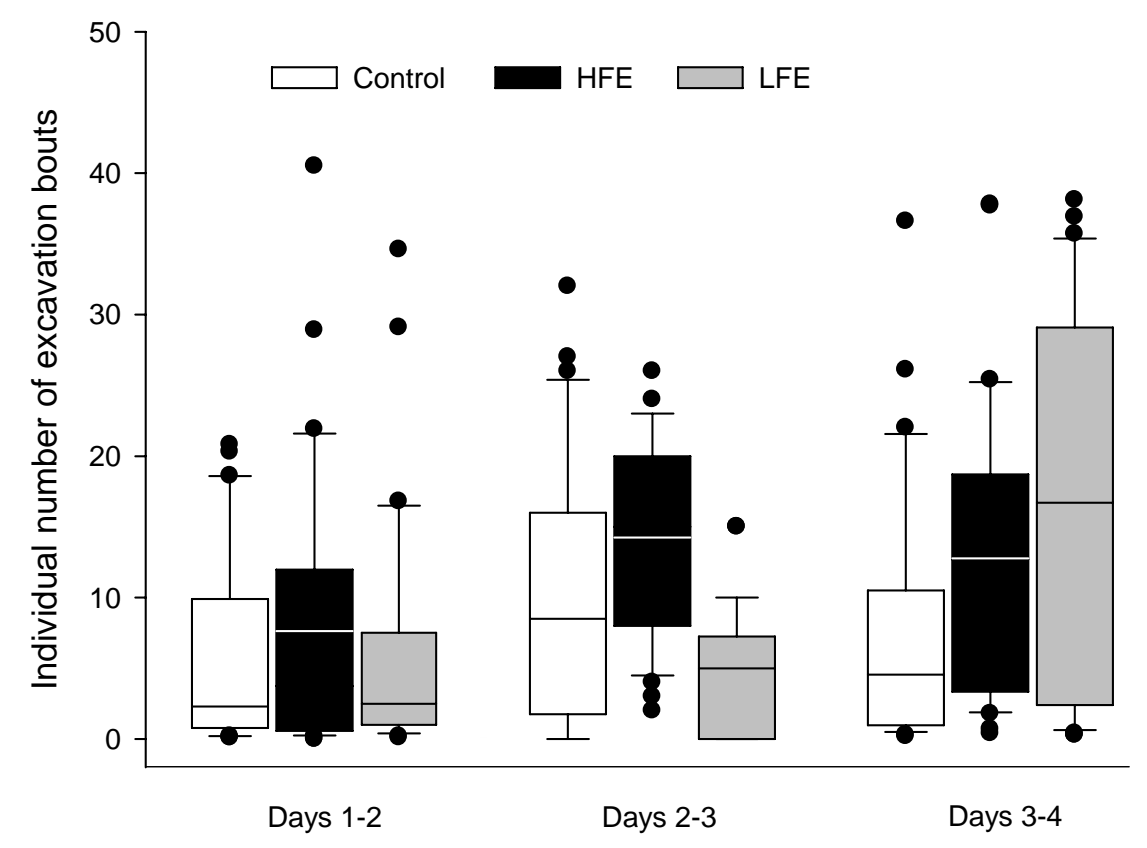

737

738 
$739 \quad$ Figure 4

740

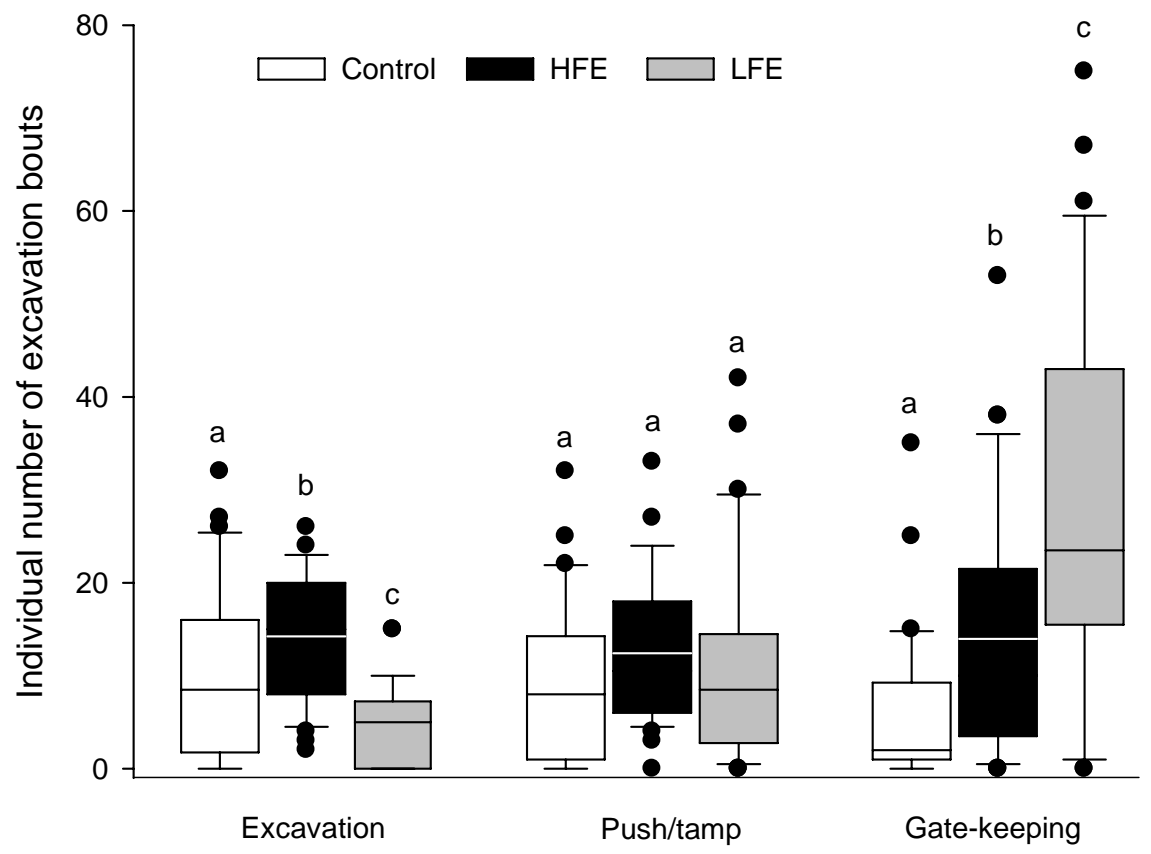

741

742 